\title{
An Analysis of Cartoons Prepared for Early Childhood Period in Terms of Child Development
}

\author{
Suat KOL* \\ Basic Education, Sakarya University, Sakarya, Turkey
}

ORCID: 0000-0002-8291-7546

\section{Article history}

Received:

03.03.2021

Received in revised form: 01.05 .2021

Accepted:

04.05 .2021

Key words:

Early Childhood Education, Cartoons,

Television.
Preschool education encompasses a period when children are at their highest capacity of learning, and when their lives are being shaped. Today, television plays an important role in child's development. Numerous studies reveal that the content of the programs watched by children are as important as determining the time spent by the children for televiewing. The purpose of this research is to examine the effects of cartoons, intended for preschoolers, on the children's development under the predetermined criteria. The research was carried out by descriptive scanning method based on document review. The study material of this research consisted of randomly selected episodes of 71 cartoons claimed to have been prepared for early childhood. The data collection tool was the Cartoon Checklist which was developed by the researcher. According to the data obtained from the research it is seen that the graphics, sound and music used in 66 of the cartoons are completely or partially appropriate. However, it is seen that the dialogues used in 65 cartoons, content used in 57 cartoons, objects used in 55 cartoons, and elements of Turkish culture in 26 cartoons are completely or partially suitable for the child.

\section{Introduction}

Preschool period is an extremely important period in the development of the child. Especially, the fact that cognitive, physical and socio-emotional development takes place in this period makes this period much more meaningful (Grotewell \& Burton, 2008). In early childhood, the child generally engages in learning behaviors at a conceptual level. It is a mental process that symbolizes the common characteristic of concepts, objects, or events. This symbolization is usually made with a word, or a name. Therefore, as the child's ability to regulate perceptual stimuli improves, concepts begin to be learned (Üstün \& Akman, 2003). However, from the moment of child's birth, all the individuals in his/her immediate surrounding should have the knowledge, perceptions and attitudes pertaining to early childhood (Küçükturan et al, 2013). It is important for the child to be able to reach a healthy development level for becoming an independent individual who is aware of his/her and others' rights, who respects such rights, and who freely expresses her/his concerns in a democratically established society.

John Dewey, one of the first educators who emphasized the importance of the environment on

\footnotetext{
*Correspondency: skol@sakarya.edu.tr
} 
the child's development, has stated that everything surrounding the child is also the loadstar of the child. Today, television is one of the most important effective factors around the children (Güngör, 2014) and all these also affect the developmental areas of children (Kurt, 2014). Despite the diversity of advanced technology, television still plays an important role on the child's development. The presence of elements, such as the variety of programs, the music and sounds used in the programs, and movies, differs television from other means of media (Coşkun \& Arslantaş, 2016). Numerous studies reveal that the contents of the programs watched by the children are as important as determining the time spent by the children for televiewing. Televiewing becomes a habit for children, and this habit determines the next generations' culture of televiewing. The televiewing rate among children may vary depending on the characteristics such as gender, race, culture, interest, curiosity, and the construct of family relationships (Çelebi, 2014).

When we consider the reasons of televiewing, we determine differences between children and adults. Most adults watch television for fun, whereas children watch the programs on television that they find entertaining to get to know and understand the world around them (Kaskun and Öztunç, 1999; cited by Öztürk \& Karayağız, 2007). In addition, the social, economic and cultural level of the audience -that the TV appeals to- is important in regulating the content. Considering the age and gender range of the audience, it has been pointed out that the majority consists of children, youngsters and women (Kocadaş, 2004; Cited By. Coşkun \& Arslantaş, 2016).

By the previous research, it has been revealed that the children in Turkey spend at least 4 hours for televiewing and $30 \%$ of it takes place during weekdays, and $70 \%$ during weekends (Elbir, 2011). Studies show that children start watching cartoons on television when they are six months old (Rashid, 2015). This circumstance may cause disadvantages due to spending of too much time before television. In addition, it can be said that the programs, which are produced by commercial concerns, which do not contribute to the development and education of the child, but on the contrary, which are allegedly produced specifically for the child, may cause serious developmental disorders, especially in socio-emotional and personality aspects (Büyükbakkal, 2007; İmamoğlu \&Şirin, 2011; Altınkılıç, \& Özkan, 2014; Omrak, 2018; Tanyıldızı \& Karabulut, 2018; Özkılıç Kabul, 2019; İmik Gümüş \& Adam, 2020;)

It is recommended for the children under the age of two not to watch TV, and for the older children to watch TV at most for one or two hours a day, and it is again recommended for the parents to always pay regard to the programs the children are watching (Cheviron, 2011; Cited By. Akcay \& Özcebe, 2012). However, it is known that children join their parents while they are televiewing. In addition, it can be said that television has a negative effect on the communication of family members, and that it prevents quality communication among them (Coşkun \& Arslantaş, 2016). By the research of the American Academy of Child Care and Health, it has been found that the children between 3 - 5 years old, who are televiewing for more than two hours a day, are being directed to vicious, restless and hyperactive behaviors (Iş1k et al., 2007). Moreover, children are being affected from the television more compared to the adults. In addition, television also has a negative effect on the social and moral development of the children as it minimizes social interaction within and outside the family (Yavuzer, 2019).

Today, there is a significant increase in the range of cartoons and TV channels broadcasting for children. In particular, the current domestic productions are better than the previous ones in terms of both quality and content, and they are drawing the attention of children 
considerably. In addition, domestic cartoons are enabling the children to have a grasp of Turkish culture. It can be said that while children have fun thanks to these television programs that support culture, they are also likely to be exposed to cultural gains. Of course, these productions have some negative or inadequate aspects as well. The interest of children in the cartoons also determines the time they spend in front of the TV. Productions that cause the children to watch television for hours have certain negative consequences.

Various scientific studies were carried out on the effects of television and cartoons on the development of the child. To illustrate, in the study conducted by Akkuş et al. (2015), the duration of televiewing among children under the age of 2 was found to be very high. Ayan and Baş (2015) found that cartoons contribute to children'slexical development . Temizyürek and Acar (2014) examined the effect of subliminal messages of cartoons on children. The research results found that there are implicit messages such as violence, aggression and sexuality in cartoons. Temel et al. (2014) found that most of the cartoons being broadcasted on television channels contain elements of violence, especially physical violence. Yaşar and Paksoy (2011) revealed by their studies that the children tend to make use of the aggressive elements -they learn from the cartoons- at the initial stages of games they play, and that they do not pursue them in the following stages of games.

The aim of this study is to reveal the effects of cartoons, produced for early childhood, on the development of the children with regard to the determined parameters. Considering the time children spend with technological equipment, especially with television, and also considering the positive or negative effects of television on the development of the children, which have been revealed by many academic studies and scientific data, it can comfortably be accentuated that the results obtained from this study may provide solutions to current problems. In addition, it can be stated that it is an important study in terms of addressing both high televiewing rate among children, and its high impact on children's mental, spiritual and physical development.

\section{Method}

\section{Research Model}

This research is a descriptive study based on document analysis within the framework of qualitative research. Descriptive scanning model is a research approach that aims to describe a past or present situation as is (Creswell, 2013). In such studies, the events and situations discussed are investigated in detail, and these studies are generally known as survey research (Erkuş, 2019). Document analysis enables the analysis of documents about a research problem produced at a specific time, or of documents on the subject produced by more than one source and at different intervals (Yıldırım \& Şimşek, 2018). In addition, there are two types of document review being general scanning and content analysis (Karasar, 2019).

\section{Data Sources}

Within the scope of the research, 71 cartoons constituted the data source. In this context, a random part of the cartoons was selected and analyzed. The cartoons, and the channels -where they are being broadcasted- are given in Table 1. 
Table 1. Data Regarding Cartoons that Constitute the Data Sources, and The Channels Where They are Being Broadcasted

\begin{tabular}{|c|c|c|}
\hline No. & Cartoon Name & Broadcasting Channel \\
\hline 1 & 44 Cat (44 Kedi) & \\
\hline 2 & Ben 10 (Ben 10) & \\
\hline 3 & Gumball (Gumball) & Cartoon Network \\
\hline 4 & King Şakir (Kral Şakir) & \\
\hline 5 & Masha and Big Bear (Maşa ile Koca Ayı) & \\
\hline 6 & Boyster (Boyster) & \\
\hline 7 & Doraemon (Doraemon) & \\
\hline 8 & Fineas and Förb (Fineas ve Förb) & \\
\hline 9 & Prenses Sofia (Prenses Sofia) & Disney Channel \\
\hline 10 & Star Wars Clone Wars (Star Wars Klon Savaşı) & \\
\hline 11 & Alien Cat (Uzaylı Kedi) & \\
\hline 12 & Lemon and Olive (Limon İle Zeytin) & \\
\hline 13 & Alvinnn! and Chipmunks (Alvinnn! ve Sincaplar) & \\
\hline 14 & Puss in Boots (Çizmeli Kedi) & \\
\hline 15 & Iron Man (Iron Man) & Kidz TV \\
\hline 16 & Peanuts (Snoopy) & \\
\hline 17 & Flying Dog Vipo (Uçan Köpek Vipo) & \\
\hline 18 & Babar and Badou (Babar ve Badou) & \\
\hline 19 & Brave Birds (Cesur Kuşlar) & \\
\hline 20 & Strawberry Girl (Çilek Kız) & \\
\hline 21 & Chloe's Closet (Damlanın Dolabı) & \\
\hline 22 & Franklin and His Friends (Franklin ve Dostları) & \\
\hline 23 & Sam Tân (İtfaiyeci Sam) & \\
\hline 24 & Truck Town (Kamyon Kasabası) & \\
\hline 25 & My Big Friend (Kocaman Arkadaşım) & Minika Kid \\
\hline 26 & Mölang (Mölang) & \\
\hline 27 & My Little Pony (My Little Pony) & \\
\hline 28 & Olly (Olly) & \\
\hline 29 & Care Bears (Sevimli Ayıcıklar) & \\
\hline 30 & Stella and Sam (Stella ve Sam) & \\
\hline 31 & Thomas and Friends (Thomas ve Arkadaşları) & \\
\hline 32 & Patched Pillows (Yamalı Yastıklar ) & \\
\hline 33 & Alpman (Alpman) & \\
\hline 34 & Art Zooka (Art Zooka) & \\
\hline 35 & Arthur (Arthur) & \\
\hline 36 & Martine (Ayşegül) & \\
\hline 37 & Owl (Baykuş) & Minika GO \\
\hline 38 & Geronimo Stilton (Geronimo Stilton) & \\
\hline 39 & Shaun the Sheep (Koyun Shaun) & \\
\hline 40 & Kratt Brothers (Kratt Kardeşler) & \\
\hline 41 & Max Steel (Max Steel) & \\
\hline
\end{tabular}




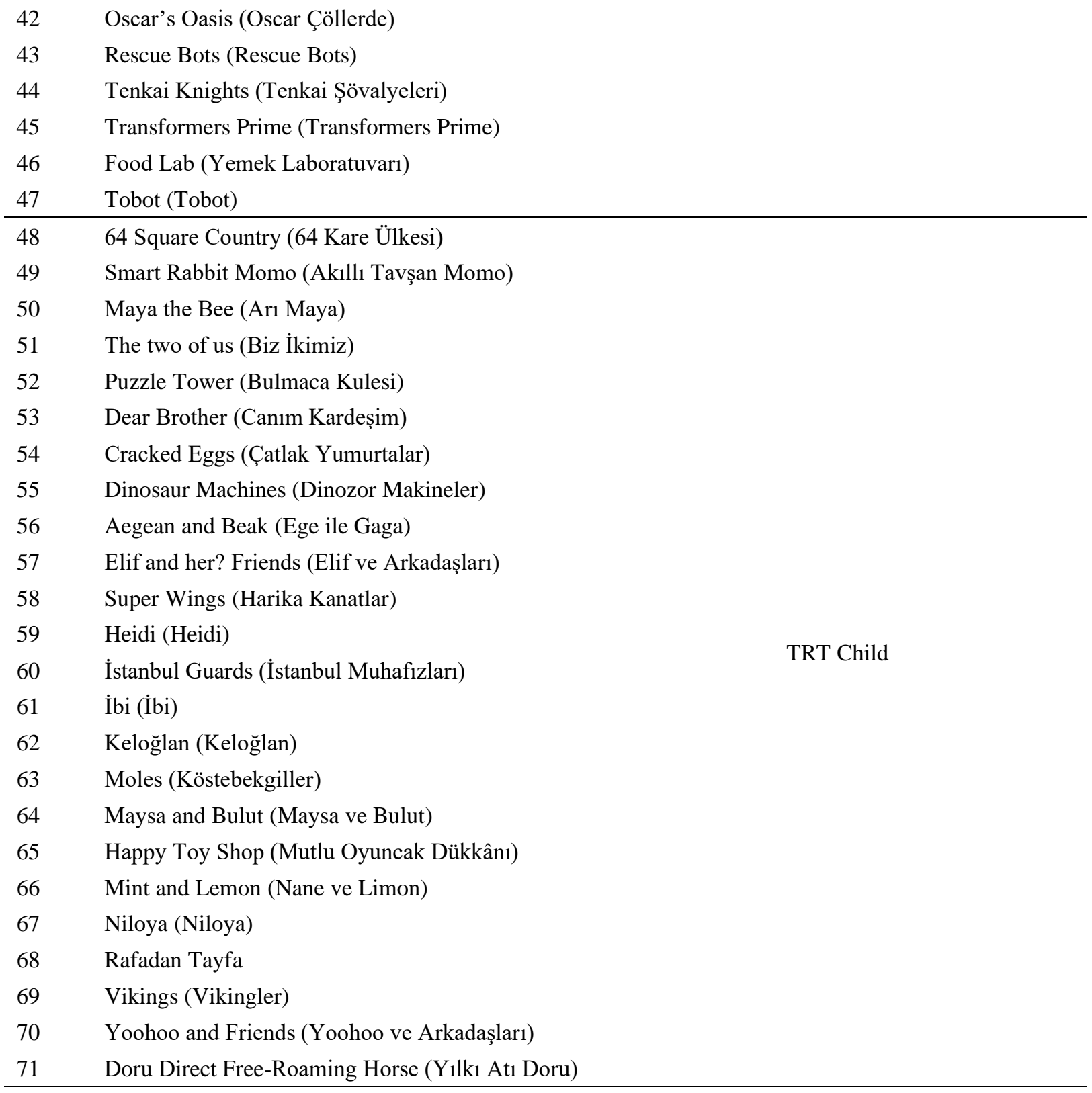

When Table 1 is examined, 24 of them are being broadcasted on TRT Child Channel, 15 on Minika Child Channel, 15 on Minika Go Channel, 7 on Disney Channel, 5 on Cartoon Network, and 5 on Kidz TV Channel. Cartoons are usually being broadcasted repeatedly during a week, and many of them are being broadcasted several times a day.

\section{Data collection tool}

The "Cartoon Checklist", developed by the researcher, was used as the data collection tool in the study. Cartoon Checklist was drafted by scanning relevant domestic and foreign broadcasts. For each item on the checklist, the criteria were determined by considering the development level of the child, and the checklist was finalized by getting the opinions of three academicians, and of five preschool teachers who are experts in fields of preschool education and evaluation.

The Cartoon Checklist consists of two parts. In the first part, the channels, where the analyzed cartoons are being broadcasted, are provided, and in the second part, 5 criteria in total, which 
evaluate the cartoons in terms of fashion and content, are included. While evaluating the cartoons, included in the data sources, in terms of the items on the Cartoon Checklist, the following features were taken into consideration:

(1) Quality of Graphics / Sound / Music: Cartoons can convey many messages and concepts to children with pictures and symbols (Dalacosta et al, 2009). The colors used in cartoon graphics are very important. Colors have physiological and psychological effects, and they affect brain waves, nervous system functions, hormonal activities, stimulate emotional and aesthetic values, and stimulate other senses (Güller, 2007; Cited By. Çukur \& Güller-Delice, 2011). In addition, color is an element that has to be emphasized in design due to its psychological effect on people (Elibol et al, 2006). While evaluating graphics / sound / music, the colors used in the graphics are expected to be vivid for attracting the attention of the children, and they are expected not to tire eyes (Dere \& Temel, 1999). On the other hand, the presence of a vibrant colorful world, and the unlimited use of visual materials are among the indispensable prerequisites for attracting individuals of all ages, and especially young children (Aydoğan, 2006). In this context, it was checked whether the graphics were prepared with vivid colors or not for grabbing the children's attention. Considering voice or vocalization, it is important for the tone of voice not to be scratchy, and for it to be calm and understandable. In addition, it is required to abstain from slang or inappropriate words due to the language development of the child, and it is required to use a wording conforming Turkish Grammar rules. Music is an indispensable phenomenon in human life. It is a dimension that children interact in their natural environments. The rhymes, songs, ballads they sing during the games, and the music they listen to may be cited as examples of this matter (Çilden, 2001). It is important for the music to have a rhythm to be enjoyed by the children such as ones having catchy tunes freefrom scratch and bumpy ones.

(2) Content: It is expected for the content of the cartoon to be at a level which can be perceived by the child, for the story to conform to the cognitive level of the child, and for the cartoon heroes to be from among the people or objects that the child may encounter in daily life, or may be aware of. In addition, it is extremely important for the content not to include any direct or indirect violence, or sexual elements. Every preschool or school-age child is exposed to sexuality, which is heavily featured in cartoons. The inclusion of the element of sexuality in cartoons is a very inconvenient situation for the development of the child (İşiyen, 2020). Various studies have shown that watching aggressive behaviors on TV, and engaging in aggressive behaviors are interrelated, and that this relationship is stronger among children. According to the results of a study, watching programs that are not suitable for children causes high rates of hyperactivity, aggression, and low social skills (Conners -Burrow et al., 2011; Cited By. Çelebi, 2014). However, contribution may be made to the mental, physical and spiritual development of the child considering her/his age and development level. In addition, the cartoon content watched affects the emotional states of the children related to that content and causes these feelings to be transferred to their lives as behavior (Kamacioğlu, 2017). In this context, the suitability of the cartoons was evaluated.

(3) Cultural Elements: National identity is one of the fundamental values that should be provided for children. The need to incorporate the characteristics of different cultures enables intercultural transfer. For this reason, it is very important that the works that contain the cultural values of their own country are available consitituting a cultural transfer tool for children (Akça and Baran, 2018). For this reason, referring to Turkish culture in cartoons, and the presence of flag, national days, poems, lullabies, folk songs, rhymes, national folklore, and any cultural object or phenomenon is extremely important in the acquisition of 
national identity by the child. It may be assumed that this will also warrant minimizing the child's exposure to foreign cultures. In fact in recent years, many elements of Turkish culture have been included in domestic cartoons. To that end, cartoons were analyzed in accordance with the specified criteria.

(4) Objects Used: The objects used in the cartoons are also extremely important. The objects need to be ones that the child knows, or that s/he is aware of, allows her/him to comprehend the content in the cartoon. if the objects used are at a level that the child may be able to comprehend and learn, then this situation contributes to child's cognitive development. In this context, the suitability of the objects used in cartoons was evaluated too considering the development of the child.

(5) Dialogues: It is important that the dialogues used in the cartoon include words suitable for the child's language development, concepts that the child can understand, contain sentence structures suitable for Turkish grammar, and contribute to the child's recipient language. Whether the specified criteria were present in the inspected broadcasts $t$ was considered as well.

The criteria in the Cartoon Checklist were scaled as "yes", "partly", and "no". While completing the checklist, the option of "yes" was checked if the cartoon examined was fully compliant with the specified criteria, the option of "partly" was checked if it was both compliant and incompliant with the specified criteria, and the option "no" was checked if it was completely incompatible.

\section{Data Collection, and Analysis}

The data collection process took about 7 months, taking into account the watching times of the selected cartoons. In this process, randomly selected parts of 71 cartoons covered by the study were recorded during the television broadcast, and the Cartoon Checklist prepared by the researcher was examined and analyzed one by one for each criterion on the checklist for 5 times. The study materials were analyzed using the descriptive analysis method being one of the qualitative research methods. In the descriptive analysis technique, the data is described and interpreted systematically, and it consists of four stages. First, a framework for descriptive analysis is created, and then data is processed according to the thematic framework, and then findings are defined, and lastly they are interpreted (Yıldırım \& Şimşek, 2018).

Instead of the validity and reliability expressions used in quantitative research, in qualitative research it would be more appropriate to use statements such as credibility, accuracy of the results, and the researcher's competence (Krefting, 1991; Cited. Başkale, 2016). The credibility of the research is provided by the criteria of credibility, transferability, reliability and approval (Shenton, 2004). In this context, 71 cartoons, that constitute the data sources, were examined in detail by the Cartoon Checklist prepared as a data collection tool.

\section{Findings and Conclusion}

Study materials were evaluated in terms of fashion and content according to the checklist developed as a measuring tool. Table 2 contains the data obtained by the evaluation of the cartoons in terms of fashion and content. 
Table 2. Distribution of Data Obtained through the Examination of Cartoons in terms of Fashion and Content

\begin{tabular}{llll}
\hline Criteria & Yes & Partly & No \\
\hline (1) Quality of Graphics / Sound / Music & 49 & 17 & 5 \\
(2) Content & 42 & 15 & 14 \\
(3) Cultural Elements & 26 & 0 & 45 \\
(4) Objects Used & 47 & 8 & 16 \\
(5) Dialogues & 49 & 16 & 6 \\
\hline
\end{tabular}

Table 2 shares, the appropriateness and quality of the graphic / sound / music of the cartoons constituting the study materials examined. It has been observed that 49 of the cartoons are suitable for children in terms of graphics, sound and image. It can be said that the graphics used in cartoons are of a quality that will attract the child's interest and understandable . In addition, it can be stated that the voices and music used in cartoons are of a nature that makes the child happy and does not cause different learning pathways. It was concluded that 17 of the cartoons were partially suitable in terms of graphics, sound and image, while 5 cartoons were not suitable.

In the second stage, it was evaluated whether the content used in cartoons is suitable for children. It was revealed that the content of 42 cartoons weas appropriate, in 15 of them was partly appropriate, and in 14 of them was not appropriate for children.

In the third stage, it was examined whether the cartoons are suitable for Turkish Culture or not. In this context, 26 cartoons have objects for Turkish Culture, while 45 cartoons does not contain any elements suitable for Turkish Culture.

In the fourth stage, the suitability of nail polishes used in cartoons was examined. In this context, it was determined that the objects used in 47 cartoons were suitable, the objects used in 8 cartoons were partially suitable, and the objects used in 16 cartoons were not suitable

In the fifth stage, it was examined whether the dialogues in cartoons are suitable for child development. In this evaluation, the length of the sentences in the dialogues, and the appropriateness of the words used in dialogues, and of the content of dialogues were taken into consideration. As the result of the evaluation, it was observed that the dialogues in 49 cartoons were appropriate, that the dialogues in 16 of them were partly appropriate, and that the dialogues in 6 of them were not appropriate.

\section{Discussion and Suggestions}

Technology actively intervenes in all areas of life today. In the recent 3 decades, the dizzying development of features in touch technologies has both increased its prevalence and has caused it to appeal to a wider user group. Technological software that appeals to children's interests and curiosity is getting cheaper and is becoming diversifiedeach passing day . In addition to digital technologies, the effect of television broadcasts, which stepped into our lives in 1923 offering quite effective and attractive opportunities with the advances of technology in recent years, on the development of the child is a fact that cannot be ignored.

Television broadcasts do not merely cover negative elements thereupon arguing that it has a 
totally negative effect would not be a correct statement to utter (Sayar \& Bağlan, 2010). What is more, as Postac1 (2016) states watching television cannot be prohibited and even poverty does not prevent watching television.

Many academic studies show that children's channels, which broadcast only for children on a 24-hour basis, have quite high viewing rates. To what extent the content prepared for children on television programs is suitable for the development of the child, and to what extent it affects the child are important matters of discussion. Because there are many programs that have been produced with commercial concerns, hence they may have negative effects rather than positive ones on the child. In this regard, the main purpose of this research is to reveal the effects of cartoons on the development of the child. In this context, the results were presented by analyzing the data.

Today, the focus is on the matters of length of time to be spent by the children for televiewing, programs they may watch, and time range proper for televiewing. In addition to being able to concretize abstract concepts, it is concluded by the research that the child achieves many cognitive gains thanks to television. But it is also the finding of many studies that television and cartoons weaken the child's ability to analyze, that they negatively affect their imagination, making the transition between imagination and reality difficult whilst increasing tendency to violence via normalizing it . Additionally, scholars pinpoint that they negatively affect child development at the social-emotional level, and that they reduce the level of the development of? psychomotor skills (Akkuş et al., 2015; Büyükbakkal, 2007; Erdoğan, 2010; Güngör, 2014; Kırık, 2013; Mustafaoğlu et al., 2018; Ünal \& Durualp, 2012).

By the first criteria of the data collection, the appropriateness level of the graphics, sounds and music of the cartoons for the child was examined. It was observed that 49 of the cartoons were appropriate for the children, 17 of them were partly appropriate, and 5 of them were not appropriate. It has been evaluated that some graphics, voices or music used in these programs may cause fear for children. In addition, voices and music have been found to be carrying content that is not suitable for children.That said, , it has been evaluated that the music used in some programs is very fast in rhythm.

By the second criteria of the data collection, the appropriateness of cartoons for the children in terms of content was discussed. In this context, it was concluded that 42 cartoons were appropriate, 15 were partly appropriate, and 14 were not appropriate. It is important that the content used in cartoons is easy for children to perceive. In this context, cartoons with content that the child can comprehend at a cognitive level was considered appropriate. In addition, it can be said that the content used in some cartoons is quite complex and incomprehensible for the child.

By the third criteria of the data collection, the appropriateness of cartoons for children in terms of cultural elements was examined. 26 of the cartoons were containing objects or content referring to Turkish Culture. In 45 cartoons, no objects or content making references to Turkish Culture were found. It is very important for children to have a grasp of Turkish culture. It can then be thought that children, who develop by internalizing other cultures, may encounter some problems at social level. In this context, children's interaction with Turkish culture, which is their own culture, in early childhood is important not only in terms of developmental aspects, but also in terms of sociological and psychological aspects. It is certain that the child, who grows up with their own culture, and who internalizes it, will be more favorable for her/his own culture, nation and state at social level. It has been observed 
that especially the cartoons broadcast on TRT Children's Channel are suitable for Turkish culture in terms of content and objects used. In addition, objects and content such as flags, folklore, traditions, proverbs that support Turkish culture were found in some programs. Most of the cartoons that make up the study material do not contain any objects or content that emphasize or support Turkish Culture.

By the fourth criteria of the data collection, cartoons were examined in terms of the objects used. In this context, it was observed that the objects used in 47 cartoons were appropriate for children, the objects used in 8 of them were partly appropriate, and the objects used in 16 of them were not appropriate for children. It can be thought that objects which cause the child to learn imperfectly, which may negatively affect the child's spirit, and which may cause unwanted emotional consequences, may adversely affect the child's development. It can be said that this may cause traumatic cases in child. It is seen that the objects used in the cartoons examined are objects that the child can understand, encounter in daily life or learn through life. In addition, in some programs there exist objects that children may not understand or be in fear of.

By the fifth criteria of the data collection, the dialogues in cartoons were examined. In this context, it was concluded that the dialogues in 49 cartoons were appropriate for children, the dialogues in 16 cartoons were partly appropriate, and the dialogues in 6 of them were not appropriate. It is important that the dialogues used in cartoons are not long or do not contain words they do not know taking into account their normal language development. However, it has been observed that the words in the dialogues used in some programs are not suitable for the child or the dialogues consist of words he does not know.

Today, there are no general criteria established to evaluate the appropriateness of cartoons for children. It can be said that the very conduct of this evaluation in light of the knowledge and experiences of the child development and education specialists, and procurement of the detailed expert opinions reveal the difficulty and value of the research. The main restriction of the study was the lack of sufficient number of similar studies, and the lack of sufficient amount of similar data confirming the obtained data. It can be thought that this circumstance can be tackled by carrying out studies of parallel nature in the future. According to the data obtained as a result of the research, the following suggestions can be made for the researchers:

- Research can be carried out by different study materials.

- The checklist used to determine the developmental effects of cartoons can be evaluated by different parameters.

- The effects of different technological tools on children's development can be evaluated.

- Research can be conducted by focusing on different age groups.

\section{Note}

Part of this study was presented orally at the 5th International Preschool Education Congress.

\section{References}

Akçay, D. \& Özcebe, H. (2012). The effect of television on the aggressive behavior of preschool children. Journal of Child Health and Diseases, 55, 82-87. 
Akkuş, S. Y., Yılmazer, Y., Şahinöz, A. \& Sucaklı, İ. A. (2015). Investigation of television watching habits of children aged 3-60 months. Hacettepe University of Health Journal $1(2), 351-360$.

Altınkılıç, Z, Özkan, H. (2014). Determination of mothers' attitudes and behaviors about the effects of TV-watching upon the health of children aged 1-6 years. Journal of Dr. Behcet Uz Children's Hospital, 4(3):186-194 https://doi.org/10.5222/buchd.2014.186.

Ayan, S. \& Baş, B. (2015). A research on the vocabulary of primary school students and the vocabulary in cartoons. Journal of Mother Tongue Education. 3(4), 84-99.

Aydoğan, Y. (2006). Organizing the home environment according to the development of the child. Family and Society, 3(10), 27-34.

Başkale, H. (2016). Determining validity, reliability and sample size in Qualitative Research. Dokuz Eylül University E-Journal of Nursing Faculty, 9(1), 23-28.

Büyükbakkal, G. (2007). Television's effect on children. İstanbul University Journal of Communication Sciences, 28, 31-44.

Çelebi, E. (2014). Preschool teachers' views and attitudes on the television watching habits of children aged 4-6. International Journal of Social Research, 7(32), 476-485.

Çilden, Ş. (2001). Music, child development and learning. G.U. Journal of Gazi Education Faculty, 21(1), 1-8.

Coşkun, Y. \& Arslantaş, H. (2016). Investigation of mothers' views on television watching of children attending preschool education. KSU Journal of Social Sciences, 13(2), 1-16.

Creswell, J. W. (2013). Research design: quantitative, qualitative and mixed method approaches. İstanbul: Educational Book.

Çukur, D. \& Güller-Delice, E. (2011). Spatial design suitable for visual perception development in early childhood. Family and Society, 7(24), 25-36.

Dalacosta, K., Paparrigopoulou-Kamariotaki, M., Palyvos, J. A. \& Spyrellis, N. (2009). Multimedya application with animated cartoons for teaching science in elementary education. Computer \& Education, 52, 741-748.

Dere, H. \& Temel, F. (1999). Approaches in pre-school education, Gazi University Kindergarten / Kindergarten Teacher's Handbook. İstanbul: Ya-Pa.

Elbir M. (2011). The relationship between television and socialization (Unpublished Master's thesis). Marmara University, Social Sciences Institute, İstanbul.

Elibol, C., Kılıç, Y. \& Burdurlu, E. (2006). Use of materials in preschool children's toys and color preferences of 4-6 years old children. Family and Society, 3(9), 35-44.

Erdoğan, S. (2010, November). The effect of television on social development and values education in early childhood period. International Conference On New Trends In Education And Their Implications "In honor of Prof. Dr. Özcan Demirel in his 50th year of service in Education" presented paper, Detail Printing, Vol I, 894-902. (11-13 November), Antalya/Turkey.

Erkuş, A. (2019). Scientific research spiral 6th edition. Ankara: Exclusive.

Grotewell, P. \& Burton R. Y. (2008). Early childhood education, issues and developments. New York: Nova Science. 
Gümüş, Ç. \& Adam, H. (2020). The effects of cartoons on preschool children: billboard designs. Ulakbilge, 47, 409-421. http://dx.doi.org/10.7816/ulakbilge-08-47-03.

Güngör, M. (2014). Television watching habits and parental attitudes of preschool children. Mustafa Kemal Üniversity Journal of the Institute of Social Sciences, 11(28), 199-216.

İmamoğlu, A \& Şirin, T. (2011). Affects the child's soul to the world of violent programs on television and the internet. EKEV Academy Journal, 15(46), 31-49.

İmik Tanyıldızı, N, Karabulut, N. (2018). Examining the preferences of children attending pre-school education towards television programs. International Journal of Humanities and Education, 4(9), 86-102.

Işık, M., Erdem, A., Güllüoğlu, Ö. \& Akbaba, E. (2007). Television and children. Education Bookstore.

İşliyen, M. (2020). Children, television and sexualism: an examinationon cartoons. Gümüşhane Üniversity E- Journal of Faculty of Communication, 5(8), 28-41. https://doi.org/10.19145/e-gifder.652500.

Kamacioğlu, B. (2017). The role of cartoon films in culture transfer and the hayao miyazaki cartoon films, Journal of Art and Design, 7(2), 1 - 18. https://doi.org/10.20488/wwwstd-anadolu-edu-tr.393478.

Karasar, N. (2019). Scientific research method concepts principles techniques. Nobel.

Kirık, A. M. (2013). Negative effects of television on developmental children and parental control problems. Education and Society in the 21st Century, 2(4), 189-198.

Küçükturan, A., Altun, A. \& Altun Akbaba, S. (2013). Applications for the development of preschool education in Turkey. The Journal of Academic Social Science Studies 6(7), 783-801.

Kurt, E. (2014). Opinions of students, teachers and parents about the impact of TRT child channel on 4-6 age group students' language development (Unpublished Master's thesis). Karadeniz Technical University, Institute of Educational Sciences, Trabzon.

Mustafaoğlu, R., Zirek, E., Yasacı, Z. \& Özdinçler Razak, A. (2018). Negative effects of digital technology use on children's development and health. Addicta: The Turkish Journal On Addictions 5(2), 227-247. http://dx.doi.org/10.15805/ addicta.2018.5.2.0051

Omrak, C. (2018). The relationship between attachment pattern, emotion regulation skills and technology use of pre-school children (Unpublished Master's thesis). Maltepe University, Social Sciences Institute, İstanbul.

Oral, Ö. \& Tekin, U. (2019). The effect of television monitoring habits on language development and play skills of children between 3-6 years: case study. Aydin Journal of Humanity and Society, 5(2), 187-214.

Özk1liç Kabul, N.D. (2019). Investigation of the effects of techonology use on social skill, play skill and language development in three years old children (Unpublished doctoral thesis). Maltepe University, Social Sciences Institute, İstanbul.

Öztürk, C. \& Karayağız, G. (2007). Children and television. Atatürk Üniversity Journal of the School of Nursing, 10(2), 81-85.

Pekşen Akça, R. \& Baran, G. (2018). Analysis of cartoons in terms of the properties of turkish culture: "Pepee Example". Yalova Journal of Social Sciences, 8(17), 215- 224. 
Postman, N. (2016). Television: fun that kills. (Trans. O. Akınhay), İstanbul: Detail. (Original air date, 1999).

Rashid, A. (2015). Impact of television cartoon channels on children in India. Journal of Indian Research, 3(2), 64-72.

Sayar K. \& Bağlan, F. (2010). Preventive psychology, emotional guidance in child education. İstanbul: Timaş.

Shenton, A. K. (2004). Strategies for ensuring trustworthiness in qualitative research projects. Education for information, 22(2), 63-75.

Temel, M., Kostak, M. A. \& Çelikalp Ü. (2014). Determination of violence in cartoons broadcasted in children's channels. Dokuz Eylül Üniversity Journal of the School of Nursing, 7(3), 199-205.

Temizyürek, F. \& Acar, Ü. (2014). The effect of subliminal messages in cartoons on children. Cumhuriyet International Journal of Education-CIJE, 3(3), 25-39. https://doi.org/10.30703/cije.321348

Ünal, N. \& Durualp, E. (2012). Television's effect on preschool children. Çankırı Karatekin University Journal of Social Sciences Institute, 3(2), 93-104.

Üstün, E. \& Akman, B. (2003). Concept development in three-year-old children. Hacettepe University Journal of Education Faculty, 24, 137-141.

Yaşar, M. \& Paksoy, İ. (2011). The effect of offensive images in cartoons on children's aggression levels during free play. Ç.U. Journal of the Institute of Social Sciences, 20(2), 279-298.

Yavuzer, H. (2019). Child psychology 34th edition. Remzi.

Yıldırım, A. \& Şimşek, H. (2018). Qualitative research methods in the social sciences. Seçkin. 